https://dx.doi.org/10.4314/jpb.v18i3.6

Vol. 18 no. 3, pp. 215-222 (September 2021)

http://ajol.info/index.php/jpb

\section{Journal of \\ PHARMACY AND BIORESOURCES}

\title{
Quality assessment of nine brands of metformin hydrochloride tablets marketed in Abuja, Nigeria
}

\author{
Olubukola A. ODENIRAN ${ }^{1}$, Olubunmi J. OLAYEMI ${ }^{2}$, Isa H. GALADIMA ${ }^{1}$, Rukaiyatu A. \\ KIRIM $^{1}$, Christianah Y. ISIMI ${ }^{2}$ and Kudirat B. MUSTAPHA ${ }^{*}$
}

${ }^{1}$ Department of Medicinal Chemistry and Quality Control; $\quad{ }^{2}$ Department of Pharmaceutical Technology and Raw Materials Development; National Institute for Pharmaceutical Research and Development, (NIPRD) Idu Industrial Area, Abuja. Nigeria.

Received $9^{\text {th }}$ June 2021; Accepted $3^{\text {rd }}$ August 2021

\begin{abstract}
Metformin is a drug of first choice in management of type II diabetes mellitus and the Nigerian market is flooded with many brands of metformin tablets. The aim of this study is to assess the pharmaceutical quality of nine brands of metformin tablets circulating in pharmacy outlets in Abuja. The brands were assessed for uniformity in weight, hardness, friability, disintegration time and in vitro dissolution using official methods. The content of active ingredient was also determined spectrophotometrically. All the brands had weights within the official limits, hardness was found to differ across the brands with values ranging between 1.20 and $11.50 \mathrm{kgF}$. Friability values were between 0.00 and $2.25 \%$, disintegration time was between 2.06 and $10.36 \mathrm{~min}$ and within official specifications for film-coated tablets. Drug release within 60 min was between 93 and 103\%, however, one of the brands fell outside the lower limit of the official specification and therefore, failed the dissolution test. Similarly, all but one of the brands were within the official specification of the percent content of active ingredient. The results highlight the need to routinely carry out market surveillance on drug products so as to safeguard the health of patients.
\end{abstract}

Keywords: Metformin hydrochloride tablets, Diabetes Mellitus, Quality assessment

\section{INTRODUCTION}

Production and sales of quality drugs is important in promoting good health in any population. A large number of ailments require the use of drugs for treatment and as such, quality drugs are necessary to prevent treatment failure and relapse [1]. Poor quality drugs globally and in Nigeria specifically, is becoming more evident based on previous researches that have been conducted [1-3]. Counterfeiting of medicine undermines the ability of Research and Development (R \& D) based companies to invest in future innovations [4]. Evidence has shown that poor quality medicines pose a significant threat to consumers as they cause adverse reactions, lack of effective treatment and possibly death [5].

Quality control procedures, which are useful tools for batch-to-batch consistency in manufacturing, should be performed for every drug product [6]. Drug products having more than three generics require analysis for biopharmaceutical and chemical equivalency.

*Correspondence. E-mail: bolakud@gmail.com Tel: +234-8033076199.

ISSN 0189-8442

(cc) BY-No 2021. Published by Faculty of Pharmaceutical Sciences, University of Jos, Nigeria. Under Creative Commons Attribution-Non-Commercial 4.0 International License. https://creativecommons.org/licenses/by-nc/4.0/ 
Diabetes mellitus is an inherited and acquired chronic metabolic disorder in which the pancreas produces insufficient amounts of insulin, or in which the body's cells fail to respond appropriately to insulin [7]. It is initially characterized by loss of glucose homeostasis with disturbances of carbohydrate, fat and protein metabolism resulting from defects in insulin secretion, insulin action or both $[8,9]$. It is considered as a major health concern today, because the prevalence has continuously increased worldwide [10].

Since the emergence of the COVID-19 in December 2019 in Wuhan, China, research interest has been geared towards identifying the risk factors for the infection, the severity of its outcome and understanding the underlying molecular mechanisms. Diabetes mellitus $(22 \%)$ and cardiovascular diseases $(22 \%)$ have been identified in numerous studies as the most common distinctive co-morbidities [11, $12,13]$. Access to quality and right medicines is a fundamental right of all citizens, however, this is a major challenge in middle- and lowincome countries. Given the limited health resources, there is need to ensure that medicines in circulation are not only affordable but are of the right quality to ensure their potency and efficacy in the management and treatment of diseases.

\section{Metformin hydrochloride}

$\left(\mathrm{C}_{4} \mathrm{H}_{11} \mathrm{~N}_{5} . \mathrm{HCl}\right)$ is 1,1 - dimethylbiguanide hydrochloride, a white crystalline powder that is freely soluble in water and soluble ethanol (95 \%), practically insoluble in acetone, chloroform, dichloromethane and ether. It has a melting point and molecular weight of $232{ }^{\circ} \mathrm{C}$ and $165.625 \mathrm{~g} / \mathrm{Mol}$ respectively. It is used for management of diabetes mellitus at a dose of $0.5 \mathrm{~g}$ to $3 \mathrm{~g}$ daily in divided doses. It is currently the drug of first choice for the management of type II diabetes; it is prescribed to at least 150 million people worldwide. The precise mechanism of action of metformin is not well understood, however, its actions have been hypothesized to include the following: decrease in glucose production in the liver (reduced hepatic glucose production and glycogenolysis), enhanced skeletal muscle sensitivity to insulin and reduction of intestinal glucose absorption and apparently, increase glycogen production by stimulation of insulin action $[14,15]$.

There has been an increase in the number of pharmaceutical products available in the market and this may be associated with the rapid increase in disease prevalence that results in high drug consumption [16]. Diabetes mellitus is one of such illnesses with high incidence and has no permanent cure, thus patients with diabetes mellitus are expected to manage this condition for life. Metformin is the first-line drug of choice for the management of type II diabetes mellitus thus, there is need for routine assay of this drug so as to ensure optimum disease management. The aim of the study is to evaluate the quality of nine (9) brands of metformin hydrochloride tablets marketed in Abuja.

\section{EXPERIMENTAL METHODS}

Materials. UV/Vis-Spectrophotometer (Agilent Cary 60), analytical weighing balance (Ohaus Analytical plus, AP250D), Ultrasonic bath, Dissolution tester (RC-6, India), Disintegration tester (Erweka ZT4-4, Germany), Erweka Friabilator, Monsanto Hardness tester, Filter paper (Whatman), glass wares, micropipette, spatula, porcelain pestle and mortar, distilled water and nine (9) brands of metformin tablets (film-coated, $500 \mathrm{mg}$ ).

Sample collection. Nine (9) brands of metformin tablets were randomly purchased from different registered pharmacies within Federal Capital Territory, Abuja, coded and subjected to analysis before their expiration dates.

Sample information. The physical requirements for packaging and labeling of drug samples which include the presence of 
National Agency for Food Drug Administration and Control (NAFDAC) registration number, batch number, manufacturing and expiration dates were checked. The samples were coded as A to I and the official guidelines were employed for the tests.

Determination of uniformity of weight. Twenty (20) tablets of each brand were randomly selected, collectively weighed and the average weight was determined. The tablets were then weighed individually and the percentage $(\%)$ deviation from official specification [17] was determined.

Hardness test. Hardness $(\mathrm{kgF})$ of ten (10) randomly selected tablets was determined using the Monsanto hardness tester and the average was calculated.

Friability test. This test is usually performed to assess the possible damage due to wear and tear that the tablet can withstand during manufacturing/transportation and this is closely related to tablet hardness. Ten (10) tablets were collectively weighed (W1), placed into the Erweka Friabilator and set to rotate at $25 \mathrm{rpm}$ for $4 \mathrm{~min}$. The tablets were de-dusted, re-weighed (W2) and friability (\%) was calculated as;

$$
F(\%)=\frac{\mathrm{W} 1-\mathrm{W} 2}{\mathrm{~W} 1} \times 100
$$

Disintegration test. Six (6) randomly selected tablets from each of the brands were placed in each of the six compartments of the disintegration tester containing distilled water maintained at $37 \pm 0.5^{\circ} \mathrm{C}$. The time taken for all the tablet particles to pass through the compartment's mesh was noted and the average time was determined as the disintegration time.

Dissolution test. This was conducted according to the official specification [18]. One (1) tablet from each brand was placed in the dissolution basket and lowered into the dissolution vessel containing $900 \mathrm{~mL}$ phosphate buffer ( $\mathrm{pH}$ 6.8) maintained at $37 \pm$ $0.5^{\circ} \mathrm{C}$. The dissolution apparatus was set to rotate at $100 \mathrm{rpm}$; aliquots of ten $(10) \mathrm{mL}$ were withdrawn at intervals of 5, 15, 30, 45 and 60 min and filtered. Then equivalent volume of the medium was replaced to maintain sink conditions. Appropriate dilutions were made and absorbance of the withdrawn samples were determined at $233 \mathrm{~nm}$ using the UV-Visible spectrophotometer. The content of metformin was calculated taking 806 as the value of $A$ $(1 \%, 1 \mathrm{~cm})$ at lambda maximum of $233 \mathrm{~nm}$. The process was repeated with two other tablets from each batch to make triplicate determinations.

Assay of metformin tablets. Twenty (20) tablets of each brand were weighed and the average weight was calculated. The tablets were finely powdered. An equivalent weight of $100 \mathrm{mg}$ of metformin hydrochloride was weighed and transferred into $100 \mathrm{~mL}$ volumetric flask, $70 \mathrm{~mL}$ of distilled water was added and mixed using an ultrasonic bath for 15 minutes and made to volume with distilled water and then filtered. The first $20 \mathrm{~mL}$ of the filtrate was discarded then $10 \mathrm{~mL}$ of the filtrate was diluted with distilled water to $100 \mathrm{~mL}$ and $10 \mathrm{~mL}$ of the resulting solution was further diluted with distilled water to $100 \mathrm{~mL}$ so as to give a nominal concentration of $10 \mu \mathrm{g} / \mathrm{mL}$. The samples were analyzed using UV-Vis Spectrophotometer at a maximum wavelength of $232 \mathrm{~nm}$ in triplicates for all the samples. Distilled water was used as blank. The percentage content of the samples was calculated using the specific absorbance of 798 according to monograph as A (1\%) [19].

\section{RESULTS AND DISCUSSION}

Nine (9) brands of metformin hydrochloride tablets obtained from pharmacy outlets in Abuja were successfully subjected to the official tests. As shown in Table 1 all the information needed about the medicines were properly printed on the elegant packages of the various brands. The information included name of brand, manufacturing date, expiry 
date, batch number, NAFDAC number, and description of the tablets. All the brands of metformin tablets used for the study were within their shelf-life at the time of investigation. The specification for packaging were met by all the samples as information about name of active ingredients, strength, dosage form, manufacturing date, expiry date, NAFDAC number, and a description of the dosage form were specified. All samples were found to be appealing.

The average weight of all tablets was found to be between 516 and $699 \mathrm{mg}$ for brands containing $500 \mathrm{mg}$ of metformin hydrochloride (Table 2). All of the tablets were found to be within limits for the range of tablet weight according to the BP specification, which stipulates that not more than one tablet should deviate from the average weight by more than $5 \%$ [20].

Table 1: Samples and packaging information

\begin{tabular}{|c|c|c|c|c|c|}
\hline $\begin{array}{l}\text { Brand } \\
\text { code }\end{array}$ & $\begin{array}{c}\text { Batch } \\
\text { number }\end{array}$ & $\begin{array}{l}\text { NAFDAC } \\
\text { number }\end{array}$ & $\begin{array}{c}\text { Manuf. } \\
\text { date }\end{array}$ & $\begin{array}{l}\text { Expiry } \\
\text { date }\end{array}$ & Tablet Description \\
\hline A & E203826 & $04-6233$ & $10 / 2019$ & $09 / 2024$ & Film coated, white, circular \& convex \\
\hline $\mathrm{B}$ & $\mathrm{J} 01321$ & B4-2914 & $07 / 2018$ & $07 / 2021$ & $\begin{array}{l}\text { Film coated, white \& round, embossed 'M 500' on one } \\
\text { side, }\end{array}$ \\
\hline $\mathrm{C}$ & BK1589 & 04-0810 & $11 / 2019$ & $10 / 2022$ & Film coated, round \& white, embossed 'HD' on one side \\
\hline $\mathrm{D}$ & G0684 & 04-3334 & $06 / 2019$ & $05 / 2022$ & Film coated, round \& off white \\
\hline $\mathrm{E}$ & FPF080120 & $04-6426$ & $06 / 2020$ & $05 / 2023$ & Film coated, round \& off white \\
\hline $\mathrm{F}$ & A200397 & $04-7945$ & $02 / 2020$ & $01 / 2022$ & Film coated, round \& convex, white \\
\hline G & FV1703 & A4-2278 & 09/2017 & $08 / 2020$ & $\begin{array}{l}\text { Film coated, Oval shaped, off white,' } 500 \text { ' embossed on } \\
\text { one side, 'FBT' on the other }\end{array}$ \\
\hline $\mathrm{H}$ & TMN018 & A4-4274 & $02 / 2018$ & $01 / 2022$ & Film-coated, flat, round, white, scored on one side \\
\hline $\mathrm{I}$ & LE16 & A4-5938 & $04 / 2019$ & $03 / 2022$ & $\begin{array}{l}\text { Film coated, white and round with 'M500' engraved on } \\
\text { one side }\end{array}$ \\
\hline
\end{tabular}

Table 2: Physical and mechanical parameters of brands of metformin tablets

\begin{tabular}{ccccc}
\hline Brand code & Uniformity of weight $(\mathrm{mg})$ & Hardness $(\mathrm{kgF})$ & Friability $(\%)$ & Disintegration time (min) \\
\hline A & $533.25 \pm^{*} 0.00$ & $2.47 \pm 0.98$ & 2.25 & $8.37 \pm 0.02$ \\
$\mathrm{~B}$ & $525.00 \pm^{*} 0.00$ & $7.20 \pm 0.42$ & 0.19 & $7.30 \pm 0.01$ \\
$\mathrm{C}$ & $559.45 \pm^{*} 0.00$ & $4.18 \pm 0.31$ & 0.00 & $5.29 \pm 0.01$ \\
$\mathrm{D}$ & $683.10 \pm^{*} 0.00$ & $6.98 \pm 0.48$ & 0.00 & $7.18 \pm 0.02$ \\
$\mathrm{E}$ & $537.55 \pm^{*} 0.00$ & $11.90 \pm 4.41$ & 2.22 & $2.06 \pm 0.04$ \\
$\mathrm{~F}$ & $516.20 \pm^{*} 0.00$ & $2.86 \pm 0.48$ & 0.38 & $4.27 \pm 0.01$ \\
$\mathrm{G}$ & $699.85 \pm^{*} 0.00$ & $11.15 \pm 1.49$ & 0.50 & $10.35 \pm 0.13$ \\
$\mathrm{H}$ & $649.75 \pm^{*} 0.00$ & $5.40 \pm 0.84$ & 0.15 & $4.01 \pm 0.03$ \\
$\mathrm{I}$ & $605.95 \pm^{*} 0.00$ & $1.20 \pm 0.42$ & 0.00 & $5.33 \pm 0.02$ \\
\hline \multicolumn{4}{c}{ = deviation from $5 \%$ as specified in the official book } & \multicolumn{4}{c}{ standard deviation }
\end{tabular}

Table 3: Percentage content of metformin in different brands of metformin tablets

\begin{tabular}{ccccc}
\hline $\begin{array}{c}\text { Brand } \\
\text { code }\end{array}$ & $\begin{array}{c}\text { Amount of drug } \\
\text { claimed }(\mathrm{mg})\end{array}$ & $\begin{array}{c}\text { Average amount } \\
\text { determined }(\mathrm{mg})\end{array}$ & $\begin{array}{c}\text { Percentage } \\
\text { content }(\%)\end{array}$ & Remark \\
\hline A & 500 & 490 & 98.0 & Passed \\
B & 500 & 520 & 104.0 & Passed \\
C & 500 & 510 & 102.0 & Passed \\
D & 500 & 485 & 97.0 & Passed \\
E & 500 & 480 & 96.0 & Passed \\
F & 500 & 490 & 98.0 & Passed \\
G & 500 & 525 & 105.0 & Passed \\
H & 500 & 515 & 103.0 & Passed \\
I & 500 & 465 & 93.0 & Failed \\
\hline
\end{tabular}




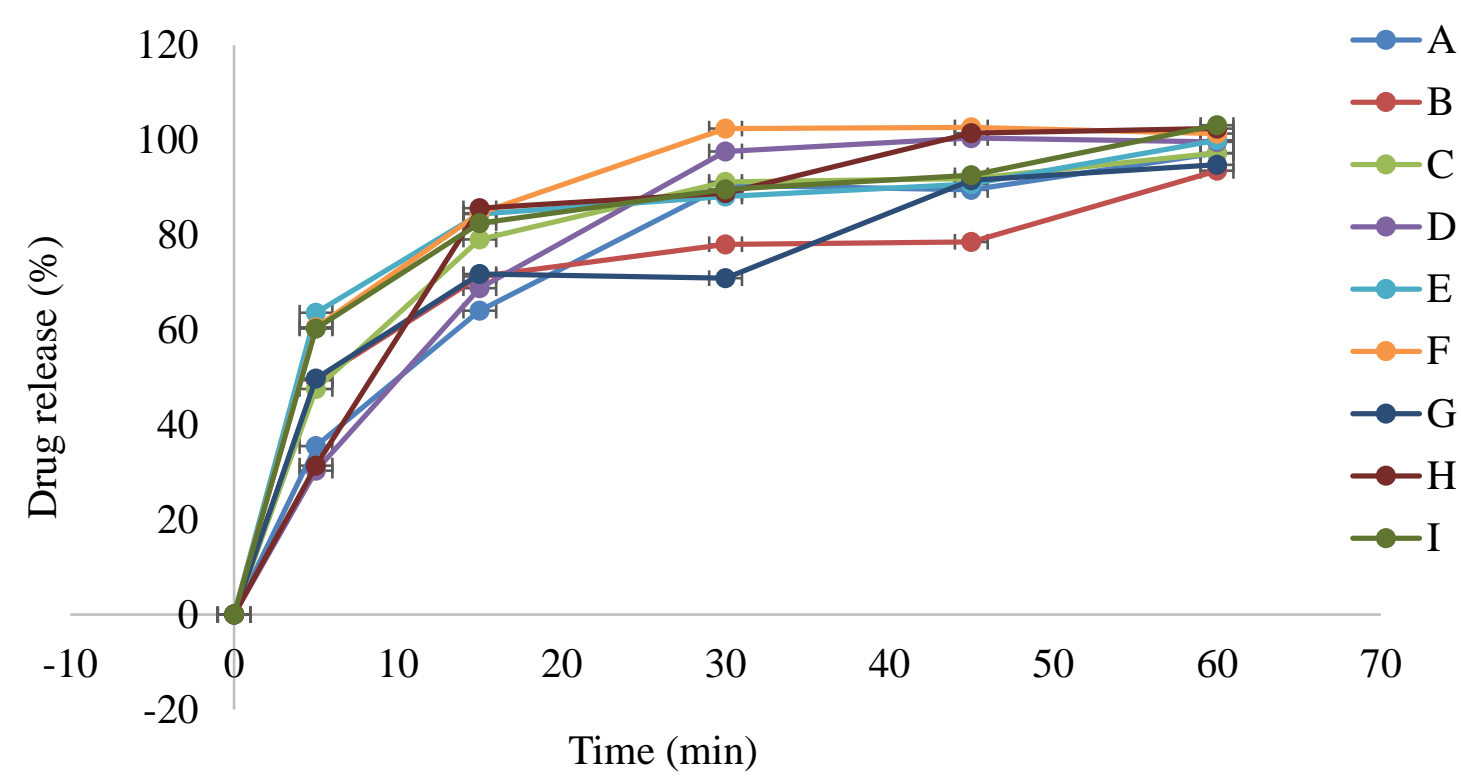

Figure 2: Drug release profile of brands of metformin tablets

Determination of uniformity of tablet weight is an important parameter because it reveals that ingredients are evenly distributed in each tablet thus preventing inconsistencies in bioavailability of the active ingredient.

Hardness is one of the parameters used to characterize the mechanical strength of a tablet; it portrays the ability of the tablet to withstand the processes involved during manufacturing, transportation, storage and use [21]. A tablet is expected to be strong enough to withstand these conditions while it is also expected to break-up to release its active medicament within a specified time. A minimum hardness of $4 \mathrm{kgF}$ is recommended for immediate conventional tablets [22] and this may vary depending on the type of excipients incorporated into the formulation and the intent of the formulation.

The results show that tablet hardness was between 1.20 and $11.15 \mathrm{kgF}$ (Table 2). Brands $\mathrm{A}, \mathrm{F}$ and $\mathrm{I}$ have the least values in the measure of hardness $(2.47,2.86$, and $1.20 \mathrm{kgF}$ respectively) while brands $\mathrm{E}$ and $\mathrm{G}$ had the highest values $(11.90$ and $11.15 \mathrm{kgF}$ respectively). Brands $\mathrm{B}, \mathrm{C}, \mathrm{D}$ and $\mathrm{H}$ had values between 4.18 and $7.20 \mathrm{kgF}$. The results show a wide difference in hardness values between the brands and could be attributed to different excipients incorporated into the tablet formulation and the manufacturing processes employed for production of these tablets. Tablet hardness is invariably related to tablet disintegration and dissolution thus, very hard tablets may not disintegrate to release the active medicament within the stipulated time leading to therapeutic failure while very soft tablets on the other hand, may not have the ability to withstand handling, transportation and storage [22].

Friability is a measure of tablet strength assessed via resistance to fracture and abrasion and percentage weight loss of $\leq 1 \% \mathrm{w} / \mathrm{w}$ is considered as an acceptable limit for tablet friability $[23,24]$. Table 2 shows that friability of the assessed tablets was between 0.00 and $2.25 \%$. Brand A with low hardness $(2.47 \mathrm{kgF})$ was seen to be the most friable with a value of $2.25 \%$ and this is because soft tablets do not withstand the stress of handling or fracture. 
Although brand $\mathrm{E}$ had very high hardness value $(11.90 \mathrm{kgF})$ it was observed to be friable and could be attributed to the use of very high compression force which could cause internal stress in the tablet leading to very friable tablets [25]. Thus, brands A and E failed the friability test but all other brands passed because they had values within the specified limit.

Disintegration is the breakup of a tablet into small granules upon its contact with a volume of fluid and this is characterized by breakdown of the interparticulate bonds which hold the tablets together [26]. It is often related with dissolution because it is assumed that the time taken for a tablet to disintegrate would indicate the time taken for the active medicament to be available for therapeutic action [27].

Disintegration time of all the brands was between 2.06 and 10.35 min (Table 2), it was observed that although brand E proved to be the hardest and most friable, it was found to disintegrate fastest. Brand $\mathrm{G}$ on the other hand with high hardness value $(11.15 \mathrm{kgF})$ took the longest time to disintegrate $(10.35 \mathrm{~min})$ showing a direct correlation between hardness and disintegration time. The remaining brands (A, B, C, D, F, H and I) disintegrated between 4.01 and $8.37 \mathrm{~min}$. All the tablets assessed passed the disintegration time test by disintegrating within $30 \mathrm{~min}$ specified for filmcoated tablets [28]. Although a relationship is thought to exist between tablet mechanical strength and disintegration time in that; strong tablets that are resistant to fracture are termed to be able to withstand breakup when in a fluid thus prolonging disintegration time, no direct correlation was observed in this assessment. This could be attributable to the different processes employed in the manufacture of these tablets [29].

Dissolution test gives insight into rate at which a drug dissolves and is made available in the biological system for optimum therapeutic response. Figure 2 shows that all the brands assessed released between 93 and $103 \%$ of metformin after 60 min with brand B having the least amount of drug release $(93 \%)$ which is outside the lower limit of the official specification (95.0 to $105.0 \%$ ) as stated by the British Pharmacopeia [18]. This shows that all but one of the brands assessed passed the in vitro dissolution test.

Table 3 shows percentage content of the tablets. The BP limit for the labelled amount of metformin hydrochloride is required to be between 95.0 to $105.0 \%$. Eight of the brands had contents within the official specification but Brand I had 93\% which is outside the lower limit specified, four (4) brands had values between 96 and 98\% (A, D, E \& F) and the remaining four (4) had percentage contents greater than $100 \%(\mathrm{~B}, \mathrm{C}$, $\mathrm{G} \& \mathrm{H})$ (Table 3). However, none of the brands had percent content greater than the official upper limit as specified in BP (105.0\%). Thus, only $89 \%$ of all brands examined passed the contents of the active ingredient while $11 \%$ failed. This implies that the eight brands that were within the monograph specification may be substituted for each other because they are pharmaceutically interchangeable. In a convenience sample of pharmacies in Lagos, some researchers found that four of eight popular brands of metformin tablets fail one or more pharmacopeial test of bioequivalence [30]

The presence of higher or lower content of metformin hydrochloride outside the monograph specification has severe consequences on the health status of the patient [31] Lower amounts of metformin hydrochloride below the accepted specification results in glucose build up in the body which may eventually lead to treatment failure, resistance and occurrence of complications which may eventually deteriorates the health of the patient(s) while, high amounts of metformin hydrochloride above the specification results in adverse effects like hypoglycemia, organ failure and 
possibly hypoglycemic related complications like coma or death [31]. This study strongly suggests the need for random sampling and routine testing of marketed pharmaceutical products within the country to ensure that their quality is in compliance with the standard operating procedures of Good Manufacturing Practice (GMP) and International Best Practices.

Conclusion. The brands of metformin tablets circulating in Abuja varied considerably in their pharmaceutical quality. Thus, this assessment highlights the importance of routine quality assessment of pharmaceutical products circulating in the market with a view to ascertain their quality to safeguard the health of the nation.

\section{REFERENCES}

1. Akunyili, D. (2004). Fake and counterfeit drugs in the health sector: the role of medical doctors, Annals of Ibadan postgraduates Medicine 2(2):19-23

2. FIP. (2010) FIP and Pfizer Launch Joint Survey at the FIP Congress, Lisbon. Available at htt://www.fip.org/www/index.php?page=latest news [Accessed on 10 March 2014].

3. Peterson, K. and Obileye, O. (2002). Access to drugs for HIV/AIDS and related opportunistic infections in Nigeria. Washington DC: USAID. Available at http://www.policyproject.com/pub/country reports/NIG_ADI.pdf [Accessed on 10 March 2014].

4. Morris, J. and Stevens, P. (2006). Counterfeit Medicines in less Developed countries; problems and solutions. International policy network. Available at htt://www.fightingdiseases.prg/pdg/IPN_counterfeits .pdf [Assessed on 10 march 2014].

5. Nsimba, S.E.D. (2008). Problems Associated with substandard and counterfeit Drugs in developing countries: A review article on global implications of counterfeit drugs in the era of anti-retroviral (ARVs) Drugs in a free market economy, east African journal of public health 5(3):205-210

6. Babalola, C.P. (2004). Bioavailability and Bioequivalence (BA/BE) Assessment. Towards Better Quality Assurance of Drugs in the 3rd Millennium. Biopharmaceutical Methods in Drug Quality Assurance,1st ed.; Olaniyi, A. A., Babalola, C. P., Oladehinde, F. O., Adegoke, A. O., Eds.; Omoadade Printing Press: Ibadan, Nigeria; p79.
7. Uddin, N., Rakib, H., Hossain, M., Sarker, A., Hasan, N.A.H.M., Islam, M.A.F., Chowdhury, M.M. and Rana S. (2014). In vitro $\alpha$ - amylase inhibitory activity and in vivo hypoglycemic effects of methanol extract of Citrus macroptera Montr. Fruit. Asian pacific Journal of Tropical Biomedicine 4(6):473-479

8. Zanatta, L., De Sousa, E., Cazarolli, L.H., Junior, A.C., Pizzolatti, M.G., Scpoganicz, B., and Silva, F.R. (2007). Effect of crude extract and fractions from Vitex megapotamica leaves on hypoglycemia in alloxan -induced diabetic rats. Journal of Ethno pharmacology 109-151-155.

9. Mahanda, S., Prova, B. and Amalesh, S. (2013). Study of hypoglycemic activity of aqueous extract of Leucas indica Linn. Aerial parts on streptozotocin induced diabeteic rats. International Journal of Pharmaceutical science and Drug Research 5(2):50-55.

10. American Diabetes A. Economic Costs of Diabetes in the U.S. in 2007. Diabetes Care. 2008; 31:596-615.

11. Pal, R. and Bhansali, A. (2020). COVID-19, diabetes mellitus and ACE2: The conundrum. Diabetes Res Clin Pract 162:108132. 10.1016/j.diabres.2020.108132 [PMC free article] [PubMed] [CrossRef] [Google Scholar]

12. Fang, L., Karakiulakis, G. and Roth, M. (2020). Are patients with hypertension and diabetes mellitus at increased risk for COVID-19 infection? Lancet Respir Med 8:e21. 10.1016/S2213-2600(20)30116-8 [PMC free article] [PubMed] [CrossRef] [Google Scholar]

13. COVID-19 Infection in People with Diabetes. Touch ENDOCRINOLOGY; Available at: https://www.touchendocrinology.com/insight/covid19-infection-in-people-with-diabetes/ (Accessed April 29, 2020). [Google Scholar]

14. Narayan, K.M.V., Boyle, J.P., Geiss, L.S., Saaddine, J.B. and Thompson, T.J. (2006). Impact of Recent Increase in Incidence on Future Diabetes Burden: U.S., 2005-2050. Diabetes Care.; 29:21142116.

15. Shaw, J.E., Sicree, R.A. and Zimmet, P.Z. (2010). Global estimates of the prevalence of diabetes for 2010 and 2030. Diabetes Research Clinical Practice; 87:4-14.

16. WHO. (2014). General information on counterfeit medicines. Availableathttp://www.who.int/medicines/services/c ounterfeit/overview/en/ [Accessedon 5 March 2014].

17. Change, R.K., Guo, X., Bumside, B.A. and Couch, R A. (2000). Fas dissolution tablets. Pharm. Tech. 24(6): 150 
18. British Pharmacopoeia (2019). Volume III. British Pharmacopoeia Commission. The Stationery Office Limited: London, UK.

19. British Pharmacopeia. (2016). Volume III, pp 832-833.

20. British Pharmacopoeia (2002). Volume III. British Pharmacopoeia Commission. The Stationery Office Limited: London, UK.

21. Odeku, O.A. and Itiola, O.A. (2003). Effects of interacting variables on the tensile strength and the release properties of paracetamol tablets. Trop. J. Pharm. Res., 2(1): 147-53.

22. Allen, L.V., Popovich, N.G. and Ansel H.C. (2004). Ansel's pharmaceutical dosage forms and drug delivery systems (8th ed.), Lippincott Williams and Wilkins, Philadelphia; p 236

23. Itiola, O.A., Odeniyi, M. A. and Adetunji, O.A. (2006). Compression, mechanical and release properties of chloroquine phosphate tablets containing corn and trifoliate yam starches as binders. Trop. J. Pharm. Res., 5(2): 589-596.

24. United States Pharmacopoeia/National Formulary (USP/NF) (2019). United States Pharmacopoeial Convention: Rockville, MD.

25. Mittal B. (2016). How to develop robust solid oral dosage forms: from conception to post-approval. Series: Expertise in pharmaceutical process technology. Academic press pp.97.
26. Okor R. S, Eichie FE, Ngwa CN (1998). Correlation between tablet mechanical strength and brittle fracture tendency. Pharm. Pharmacol. Commun. 4: 511-513.

27. Parmar, V. K., Desai, S.B. and Vaja, T. (2014). RP-HPLC and UV spectrophotometric methods for estimation of pirfenidone in pharmaceutical formulations. Indian J. Pharm. Sci. 76(3): 225-229.

28. United States Pharmacopoeia/National Formulary (USP/NF) (2003). United States Pharmacopoeial Convention: Rockville, MD, p. 2227.

29. Eichie, F.E., Arhewoh, M.I., Isesele, J.E. and Olatunji, K.T. (2009). In-vitro evaluation of the pharmaceutical quality of some ibuprofen tablets dispensed in Nigeria. African Journal of Pharmacy and Pharmacology. 3(10). Pp 491-495

30. Olusola, A.M, Adekoya, A.I. and Olanrewaju, O.J. (2012). Comparative evaluation of physicochemical properties of some commercially available brands of metformin $\mathrm{HCl}$ tablets in Lagos, Nigeria. Journal of Applied Pharmaceutical Science. 2(2): 41-44

31. Board on Global Health; (2013). Institute of Medicine; Buckley GJ, Gostin LO, Editors. Countering the Problem of Falsified and substandard drugs. Washington (DC): National Academies Press (US) 